respects agrees with the characters of this genus, so far as they are given in the Report. The variety of Diplodus with a single spine also exhibits the same peculiar feature.

The characters of the four other genera, described in the paper; are too concisely given in the Report to enable me to form any decided opinion respecting them, though $I$ venture to think that more than one are apparently only varieties of previously described forms.

Gasforth, Newcastre-on-Tyne,

Thomas Aтther. July $15,1867$.

THE WEAVER CLAYS.

To the Editor of the Gmologigal Magazini.

SIR,-When I paid my first visit to the Ribden Fire-clay Pit several years ago, I formed pretty much the same opinion as that now held by Mr. Green, viz., that the deposit consisted of local washings from surrounding strata, gathered into a wide fissure. I have since then, however, made many journeys to the district, and I have convinced myself, from a leisurely examination of all the openings which have been made in search of "clay," that the deposit is a very extensive one, and truly of marine origin. The beds extend over an area of nearly two miles in length, with a width varying from a quarter of a mile to a mile and a half.

Mr. Green is in error in attributing the parentage of the sands and clays to the Bunter. The greater portion of the deposit has certainly been derived from the Millstone grit strata that still prevail so largely to the westward of Weaver. Immense blocks of grit, of different degrees of hardness and coarseness, are thickly embedded in the sands at Caldon Low, and they are to be seen in every state of degradation, from the hard unperished stone to incoherent sand, that merely shows where the blocks previously existed, by a slight difference of tint from that of the sand of the matrix. A very small percentage only of the sands of the deposit have been derived from the Bunter.

The sands in some parts of the deposit are as white as the best Alum Bay sand. They are so free from iron that, at my recommendation, they have been tried lately for glassmaking, and they have been found to answer very well. Bunter sand could scarcely, under any circumstances, have been washed sufficiently free from iron to stand this manufacturing test.

With regard to the "Boulder-clay Drift," I must state it to be my firm conviction that the red bed which overlies the "Weaver Clays," in some parts to the thickness of from twelve to fifteen feet, does really belong to that formation. It lies in many places where it could not have been deposited by subaërial action; it contains rounded and subangular masses of stone of many formations, and it has itself been subjected to after-denudation. It is also of similar character to the red clay that is seen to fill the fissures in Caldon Low, at a height of twelve hundred feet; and to be piled on the 
floer of Thor's Cave, at about nine hundred and fufty feet abeve ther sea-level.

I do not understand Mr. Green's hesitation to admit that the sea covered the Derbyshire Limestone Hills at the Glacial epoch, for I read in the valuable Ordnance Memoir of the country round Stockpoxt, Macclesfield, Congleton, and Leek, by Messrs. Hall and Green, and with the paragraph itself bearing the initials A. H. G., that "In an outlying patch of sand and gravel about three miles from. Macclesfield, on the Buxton road, at a height of about twelve hundred feet above the sea, Mr. Prestwich found shells; and Mr. Sainter tells me that he has collected there Turritella, Cardium edule, and others." Now the point on the Axe Edge range here indicated is only about sixteen miles from Weaver, and the highest tops of the Weaver range are not more than about twelve hundred and twenty feet above the sea; the Weaver Clays and the Boulder Drift, the subjects of the present communication, lying at from one thousand. to one thousand and fifty feet.

We have not yet found shells in the drifts of the neighbourhood; but we have every other proof that can be desired of their marine origin.

The chief geological interest that attaches to the "Weaver Clay" deposit is, that it proves a submersion of this part of the country at some period between the Triassic and the Boulder-clay epoehs, at. which latter period our hills were undoubtedly again sunk beneath. the sea.

I am, Sir, Yours faithfully, EDway Brows.

BURTON.EPON-TrRnt.

12 th July, 1867.

\section{THE LOB-WORM EPOCH.}

To the Eiditor of the Geological Magazine.

Srn,-Mr. Baily (Figures of Characteristic British Fossils, p. 12) tells us that the only remains of animals in the Cambrian rocks (the oldest fossiliferous British strata) are those of worms; and (p. 3) that these worms were "allied to the recent lob-worm." It is true that he remarks (p.12) that "it has been argued, and with reason, that this apparent paucity of organic remains may have arisen from the nature of the deposit . . . and that there may have been a more varied assemblage of life during this epoch . . . as this, however, is necessarily conjectural, much importance cannot be attached to it." Now is the negative argument not also "conjectural ?" and is it not a most absurd conjecture that because in certain marine strata, in a certain place in England, signs of no life are found save. that of worms, that in the "epoch" or time when those strata were formed no animals existed on the terraqueous globe save worms? Is this not "conjectural?" and most absurdly conjectural? Continents. from the denudation of which the Cambrian strata were formed must have existed for countless millions of years. And were these continents, and the land, and the water, of the whole terraqueous globe uninhabited, except by marine lob-worms? This is a curious 